\title{
Críticas e Denúncias: A Configuração da Ação Coletiva contra a Remoção de Favelas do Rio de Janeiro
}

\author{
Alexandre Magalhães \\ Universidade Federal do Rio de Janeiro (UFRJ), Rio de Janeiro, RJ, Brasil. E-mail: \\ alex.socio@gmail.com
}

\section{INTRODUÇÃO}

F m dezembro de 2009, a prefeitura do Rio de Janeiro divulgou uma - lista de 119 favelas a serem parcial ou totalmente removidas na cidade até 2012. Esse levantamento era uma manifestação da reorganização dos aparatos estatais com vistas à retomada de uma política que se considerava já superada, ou ao menos deslocada no campo das ações governamentais: a remoção de favelas ${ }^{1}$. Contudo, a divulgação da lista pode ser compreendida como a culminação de um debate que fora recuperado naquele ano, especialmente por autoridades públicas e alguns meios de comunicação. Tal debate teve como elemento principal de discussão a posição das favelas no âmbito das propostas de reordenamento urbano que então se esboçavam e que atualmente ganham forma na cidade do Rio de Janeiro.

Diferentes justificativas foram mobilizadas para legitimar a ação estatal no sentido da implementação de um programa de remoção de favelas. Apesar de serem empregadas simultaneamente em diferentes ocasiões, é possível afirmar que cada justificativa foi delineada em momentos e situações diversas. Em primeiro lugar, no período em que se armou o debate acerca da posição da favela na configuração menciona$\mathrm{da}$, o argumento usado foi o da "ordem", baseado em seu inverso, a chamada "desordem urbana". Em segundo lugar, por ocasião das chuvas que atingiram a cidade do Rio de Janeiro em abril de 2010 e mata-

DADOS - Revista de Ciências Sociais, Rio de Janeiro, vol. 60, no1, 2017, pp. 209 a 238. 
ram centenas de pessoas, a questão mobilizada foi a do "risco" 2 . Por fim, outra justificativa que passou a compor o "repertório da remoção" (Magalhães, 2013) foi a do "legado". Isto é, os preparativos da cidade do Rio de Janeiro para receber os Jogos Olímpicos de 2016 permitiriam que à cidade fossem deixados inúmeros legados, bens materiais e imateriais que tornariam a vida local melhor.

Desta configuração de circunstâncias desdobraram-se posteriormente as ações concretas levadas a cabo pela administração pública. Diferentes estratégias e mecanismos foram acionados para efetivar as inúmeras remoções programadas. Durante esse período, diversas tecnologias estatais foram empregadas para gerir e implementar formas de controle populacional. Todas essas técnicas buscaram, em um determinado campo de forças por elas instaurado, conduzir e controlar os moradores de favelas, a partir de uma intervenção que implicava pôr em circulação um conjunto de pessoas pelo espaço urbano, redefinindo os usos e fluxos de diferentes áreas da cidade.

O argumento atualmente em uso me parece ser o que Telles (2010), citando Frederic Gros, chama de "lógica da intervenção". Marcando uma passagem decisiva entre o "tempo da política" e o da "administração das urgências", essa lógica implica o fato de que, inversamente ao que ocorre na política (considerando seus protocolos de deliberação e negociação), a intervenção seria conduzida por critérios chamados técnicos de competência daqueles considerados como especialistas, e "é acionada para restaurar uma ordem ameaçada, restabelecer harmonias rompidas, reparar disfunções, encontrar soluções" (ibidem:157). A intervenção teria como finalidade a gestão dos riscos, constituindo-se de maneira pontual, em uma dada territorialidade, mas sempre de forma deslocante, na medida em que os alvos e os problemas podem ser redefinidos. Como ressalta a autora: "modos de gestão das populações, de seus fluxos e movimentos" (idem:157).

Inspirando-me em Hirata (2010), quando ele diz que a análise dessas dinâmicas aponta para um duplo aspecto - por um lado, lança luz sobre os pontos de incidência do poder, aqui entendidos como as técnicas de gestão dos moradores das favelas em processo de remoção e, de outro lado, sobre como nesses pontos de incidência também se configuram as estratégias mais variadas de resistência às intervenções - faz-se necessário mencionar que o campo de intervenção configurado pelas ações estatais implicaria não somente variadas formas de controle e 
gestão, mas igualmente levaria à formação de inúmeras modalidades de questionamento por parte daqueles diretamente afetados por suas técnicas.

Nesta angulação, abordarei neste artigo, a formação da ação coletiva por parte dos moradores de favelas ${ }^{3}$ do Rio de Janeiro no período compreendido entre 2009 e 2012. Além disso, procurarei compreender de que maneira as concepções dos atores interferem em sua definição do problema público. Pensar a construção da mobilização dos moradores de favelas em torno desse problema na atualidade, nos leva a considerar não apenas a complexidade dos contextos de sua atuação, mas também as inúmeras formas de engajamento possíveis, que variam de acordo com a situação.

Além da introdução e da conclusão, este artigo se estrutura em quatro seções. A primeira apresenta o seu ponto de partida analítico. Em seguida, busca abordar o movimento que vai da indignação à construção da causa pública por meio de um trabalho de constituição de um problema público. Ainda nesta seção, trato do eixo central deste trabalho: a crítica aos "procedimentos". Na seção seguinte, discuto o que chamo de desqualificação moral, processo no qual as agências estatais ignoram ou diminuem as capacidades avaliativas e cognitivas dos moradores de favelas nas ocasiões de remoção. Por fim, abordo como as fontes das queixas que fazem emergir certas críticas se dão em torno do "discurso de verdade" produzido pelos "laudos técnicos" elaborados pela prefeitura para justificar a remoção.

\section{PROCESSO DE CODEFINIÇÃO E DE CODOMÍNIO DE SITUAÇÕES PROBLEMÁTICAS}

Do ponto de vista analítico, busco afastar-me das abordagens extremamente normativas que se impõem sobre o conjunto das práticas sociais e pressupõem formas de ser e agir. Sem negar os aportes propostos por algumas teorias (como aquelas que foram reunidas sob o rótulo de Teoria dos Novos Movimentos Sociais), pretendo apresentar uma contribuição às abordagens sobre a ação coletiva partindo não de cima, mas de baixo, isto é, das práticas efetivas empreendidas pelos próprios atores.

A Teoria dos Novos Movimentos Sociais, ao apresentar uma perspectiva que se situava no que se convencionou chamar de demandas "pós-materiais", certamente contribuiu para o enriquecimento das análises ao trazer para o centro do debate não mais (ou, pelo menos, 
não somente) o mundo do trabalho, mas a cultura (Alonso, 2009; Gohn, 2008). Ou seja, as lutas no mundo contemporâneo não se originariam mais no sistema produtivo, mas em contestações socioculturais. Além disso, novos formatos foram sendo instituídos, identificados como refratários às formas tradicionais de organização e ação políticas.

Contudo, como afirma Doimo (1995), apesar do reconhecimento de que as mobilizações, traduzidas como novas e inovadoras, se caracterizam por sua diversidade, pelo seu caráter fragmentário e mesmo localizado, não seria incomum o fato de que boa parte das interpretações feitas neste marco teórico reintroduza o que a autora chama de "velho desejo de unidade". Ademais, como foi intensamente discutido no Brasil, os "novos movimentos sociais" se constituíram contra e apesar do Estado, e seriam prenhes de um potencial transformador capaz de alterar a sociedade. Apesar das modificações e inflexões ocorridas nessas teorias, como a proposta por Touraine (2006) em relação à análise da ação coletiva na América Latina e a incorporação, por parte dos analistas do Processo Político, das contribuições de Erving Goffman, principalmente sua ideia de performance (Alonso, 2009), parece-me que elas ainda insistem em uma dimensão extremamente normativa, visto que partem sempre do pressuposto de uma virtual capacidade de transformação social que os movimentos sociais teriam.

Essa compreensão também permeou (e, em certa medida, continua permeando) as análises sobre a ação coletiva no Brasil. Especialmente a partir do final da década de 1970, quando se intensificaram as experiências de mobilização coletiva, sobretudo nos espaços urbanos, a novidade em questão foi vista como a possibilidade de redenção nacional. Termos como "autonomia", "novos sujeitos políticos", "democracia de base", "popular" entre outros, mobilizados pelos atores em disputa, tornaram-se recorrentes nas análises e levaram à polarização autonomia-institucionalização, como afirmam Machado da Silva e Ribeiro (1984), não obstante as precauções interpretativas já presentes em Santos (1981) e Cardoso (1984), que tentavam demonstrar que a polarização não fazia sentido ${ }^{4}$.

Posto isto, compartilho o ponto de partida de Doimo (1995), isto é, seria necessário abdicar de qualquer "otimismo teórico apriorístico". Em vez de pressupor o que são ou o que devem ser os movimentos sociais, este trabalho descortina a possibilidade de estudar a ação coletiva não pela 
definição formal do bom senso acadêmico, mas pelo senso comum prático dos atores que definem o que é, durante o que fazem, a ação deles.

Uma abordagem que parece interessante à análise ora proposta é a que se aproveita dos recursos do pragmatismo em suas variadas formas. Como afirma Cefaï (2009), uma análise baseada no pragmatismo, diferentemente de uma postura de exterioridade em relação àquilo que descreve, pretende acompanhar, muito de perto, os atores e suas "experiências" e "perspectivas". Ainda de acordo com este autor, um procedimento de tal tipo focalizará o esforço analítico e descritivo "em modalidades de engajamentos em situações". Outra dimensão importante nessa abordagem é a consideração de que uma determinada dinâmica de ação coletiva seria um "processo de codefinição e de codomínio de situações problemáticas".

A análise pragmatista procede à apreciação de situações nas quais as formas de experiência, de opinião e de ação pública não cessam de se instituir (Cefaï, 2002). Esse processo ocorre juntamente com uma dinâmica de produção de atores individuais e coletivos, na qual a identidade não seria totalmente estabelecida de início, mas seria produzida no curso de interações. Neste sentido, de acordo com Trom (2001), a investigação centrada na constituição da ação coletiva deverá referir-se a sequências breves de ação em função das quais o coletivo atuante adquiriria uma consistência própria, surgindo como parte da realidade compartilhada ${ }^{5}$.

Dito isto, cabe agora tecer alguns comentários acerca de como a análise será aqui estruturada. A apreciação que farei a seguir partirá das observações realizadas primordialmente entre o final de 2009, quando do anúncio da remoção por parte da prefeitura de 119 favelas na cidade, e o final de 2011, ocasião do desmonte desmonte do Núcleo de Terras e Habitação (Nuth), da Defensoria Pública ${ }^{6}$.

A razão deste recorte temporal é que durante esse período, considero terem se constituído dinâmicas de mobilização em torno da remoção, que envolveram múltiplas dimensões, situações, atores (individuais e coletivos), em diversas regiões da cidade organizadas principalmente em torno de uma articulação circunstancial resultante da ação de três "coletivos referências": o Conselho Popular, a Pastoral de Favelas e o Nuth. 
Embora essas inúmeras dinâmicas e diferentes formas de articulação entre diversos atores anteriormente ressaltadas possam ser observadas no período posterior ao recorte aqui feito, o que me interessa, sobretudo, é chamar a atenção para uma espécie de ponto de coagulação movimentalista que se formou naquele período, notadamente por coincidir com a ocasião de maior incidência das intervenções estatais visando à remoção de favelas.

Isto é, o foco da descrição na constituição da ação coletiva possível nesta conjuntura se deu justamente no momento em que ocorreu a ação massiva dos aparatos estatais visando realocar moradores de favelas da cidade. Apesar de tais processos terem continuado posteriormente, eles não ocorreram na mesma velocidade e intensidade com que aconteceram no período analisado por inúmeros fatores, sendo um deles a própria veiculação de críticas e a construção de denúncias por moradores das primeiras favelas a serem removidas, que acabaram sendo processadas, em parte, por algumas instituições públicas.

\section{“Minha Vida Parou". E Agora, o que Fazer?}

A vida vivida até então seria lançada em uma nova direção, contra a própria vontade, modificando e alterando todo o conhecimento prático e tácito a partir do qual tudo ao redor fazia sentido. Uma das consequências mais importantes (e mais problemáticas, do ponto de vista dos moradores dessas localidades) foi o fato de que parte considerável dos percursos e trajetos corriqueiros dos moradores das favelas em processo de remoção ficariam sujeitos a dinâmicas que anteriormente ou lhes eram completamente desconhecidas ou não figuravam em seu horizonte de expectativas até aquele momento. O que era o típico, o dado, o inquestionável da vida cotidiana, sofreu então um abalo incomensurável.

Expressões como "eu fui pego de surpresa" e "eles querem uma coisa que não coloquei à venda" evidenciam o início de uma fase de angústias e tensões que acompanharam os moradores na sequência dos primeiros contatos com os agentes da administração pública. A consequente alteração em suas rotinas de vida provocou inúmeras reações, ativando as mais variadas modalidades de ação e provocando reajustes nas formas usuais de comportamento para lidar com a nova situação. Esse foi o momento do "que fazer" diante dos novos aconteci- 
mentos, para os quais eles não estavam preparados e nos quais o que era previsível havia deixado de ser.

Em muitos casos, a primeira reação fora a indignação e uma recusa imediata ao que estava acontecendo, de algo que lhes fugia completamente ao controle: "A prefeitura vim sem mais nem menos, sem ao menos um projeto, dizendo que a prefeitura vai pegar a minha casa, não admito mesmo, não aceito" ${ }^{\prime 7}$. Não admitir, não aceitar a falta de projeto, a imprevisível investida: esses sentimentos e sensações, do que era naquele momento considerado insuportável, extrapolaram-se e podem ser vistos como o ponto de ignição de todo o trajeto que será percorrido posteriormente. Como afirma Cefaï (2011:74):

a experiência do que é injusto, mas também do que é indecente e inconveniente, decorre do modo passivo do 'ser afetado' pela situação, antes dessa experiência ser formatada segunda as modalidades práticas dos regimes da crítica e da denúncia.

Neste sentido, é possível compreender que a construção de uma crítica (e a configuração de uma ação coletiva) pressupõe a vivência de uma experiência incômoda que levaria à queixa, seja esta (a experiência desagradável) sofrida pelo crítico ou o resultado de uma comoção pelo destino de outra pessoa. Essa experiência estaria na origem da indignação (Boltanski e Chiapello, 2002), para os quais nenhuma crítica poderia se constituir sem a consideração desta movimentação inicialmente emotiva.

Contudo, o reconhecimento do sofrimento e da indignação provenientes da sua observância não conduz diretamente à construção de uma crítica estruturada e articulada, haja vista a necessidade de a crítica apoiar-se em elaborações teóricas e em uma retórica argumentativa para expressar e ser capaz de realizar um exercício de tradução do sofrimento individual (singular, particular) em termos (e em práticas) que façam referência ao bem comum (ao geral, ao coletivo). Para os autores existiriam

dois níveis de expressão de uma crítica: um nível primário, situado no âmbito das emoções, que é impossível fazer interromper e que sempre está disposto a inflamar-se diante da presença da menor situação nova que force à indignação, e um nível secundário, reflexivo, teórico e argumentativo, que permite manter a luta ideológica e é a fonte de conceitos 
e esquemas que permitirão ligar as situações históricas que pretendem submeter a crítica a valores universais (ibidem:48).

Uma pessoa apenas se movimenta quando algo "está fora do lugar", quando o curso rotineiro da ação é interrompido por algum motivo. Boltanski e Thévenot (1999) definem esses instantes como "momentos críticos" $^{\prime \prime}$. A demonstração de descontentamento se desdobra então em uma controvérsia, em uma disputa. A transição do que Cefaï (2011) chama de "choques afetivos", mas também sensíveis e morais, como os vivenciados pelos moradores de favelas submetidos aos processos de realocação, àqueles julgamentos traduzidos num horizonte de publicidade, dar-se-ia somente através da "definição da situação problemática" e, articuladamente, a partir da produção de certos padrões de ação e "formulação de boas razões para agir".

Neste sentido, interessa saber, sobretudo, quais os recursos cognitivos e morais que necessitam ser mobilizados para que um problema que diz respeito inicialmente apenas a um indivíduo possa ser generalizável a um grupo ou a outros coletivos. Inspirando-se nas análises de Gusfield, Freire (2005), afirma que um determinado problema social não seria, em si, um problema público, na medida em que nem sempre demandará uma resposta pública. Posto isto, a ascensão de um assunto privado a um problema público dependeria de uma "ação construtiva", isto é, tal processo apenas ocorreria quando um determinado grupo, que se considera responsável em fazer algo, apropria-se do assunto.

Como afirmado anteriormente, constituir-se-iam diferentes formas para lidar com a nova condição imposta desde o exterior por forças que não podem ser controladas. Tal como analisado por Cefaï (2011), a forma como moradores de uma área degradada de Paris recebiam a notícia de um projeto de requalificação urbana, para o qual não foram chamados a participar e nem sequer haviam sido consultados, poderia muito bem ser deslocada para compreender, em parte, as inúmeras situações de remoção que pude presenciar. Alguns pontos dessa espécie de roteiro analítico-prático apresentado pelo autor se encontraram presentes num caso ocorrido em uma favela da Zona Oeste da cidade, removida entre 2010 e 2011 para a construção de uma via segregada de ônibus: inicialmente, uma exposição pública de uma obra viária, diretamente feita pelo prefeito da cidade, em que a questão das favelas da região foi tratada como "já resolvida", mesmo que os moradores ali presentes não tenham sequer sido comunicados sobre o que lhes acon- 
teceria e se, realmente, haveria algum impacto em seus locais de moradia.

Na sequência, a "pulga atrás da orelha": o que vai realmente acontecer. Aqui, o acaso teria a sua parte: num certo dia, quando um morador da favela em questão estava num supermercado da região, ouviu uma conversa entre duas pessoas, provavelmente moradoras dos condomínios de classe média alta da área, em que se afirmava que haveria uma audiência pública para discutir detalhes da realização da referida obra viária, que causou diversos impactos na região, sobretudo para as inúmeras atividades econômicas ali existentes, em especial, as comerciais. A isso, juntaram-se os rumores de uma possível remoção, haja vista que há muitos anos já ocorrera uma tentativa frustrada da prefeitura de retirá-los dali, justamente a pretexto de obras de ampliação da avenida que passa ao lado da favela e, por isso, os moradores teriam que abandonar o local.

Posteriormente, alguns moradores foram à reunião em questão, mesmo sem terem sido convidados. Chegando lá, foram impedidos de fazer qualquer pergunta. Como estratégia, um deles pediu a um morador de um conjunto de classe média (que ele já conhecia porque havia trabalhado para este) que fizesse uma pergunta sobre as favelas que estavam no traçado da obra. A resposta da autoridade pública presente naquele encontro foi lacônica e evasiva: "já estão resolvidas". As pessoas foram embora com esta frase na cabeça, sem entenderem muito bem o que significava. Além disso, na sequência daquela resposta confusa, o morador de classe média questionou a afirmação da autoridade pública e ouviu que "nada vai impedir a obra". Esse fato contribuiu muito para aumentar as suspeitas e o incômodo que já havia sido causado entre os moradores presentes. A notícia circulou pela favela e reforçou os estados de ansiedade coletiva, fazendo com que o passo seguinte fosse o início de uma interpelação às agências públicas a partir da pergunta: por quê? Neste ponto, tal como afirma Cefaï (2011), "abre-se a dinâmica temporal dos prognósticos, das denúncias e dos protestos".

A interpelação e a dinâmica levaram, contudo, a diferentes formas de buscar uma resposta à nova situação criada pelos processos de remoção, respostas estas não necessariamente coletivas. As maneiras de reencaixar a situação em um enquadramento que, por um lado, desse sentido e, por outro, oferecesse uma solução satisfatória, variou muito: 
desde a aceitação das propostas feitas pela administração pública (novo imóvel num conjunto habitacional, indenização ou compra assistida), especialmente sob a justificativa do "medo de não ganhar nada" (como muitas vezes ouvi ao longo deste período, posicionamento alimentado pela ação dos agentes públicos que atuavam na ponta desses processos). Passava por uma espécie de "manipulação", às vezes individual, às vezes coletiva, dos termos que a nova circunstância lhes havia imputado - como fazer algumas críticas públicas, mas, ao mesmo tempo, sem comunicar aos demais moradores; negociar com as agências da prefeitura melhores condições de saída, em troca de colaborar com o processo de remoção; ou mesmo quando o presidente da associação de moradores "vendia" a localidade. E passava também pelo acionamento de redes clientelistas já conhecidas (como determinados políticos ou seus cabos eleitorais, para quem, inclusive, já se houvesse trabalhado em algum momento) até pelo acionamento das redes militantes formadas por um emaranhado de organizações e instituições públicas, tais como movimentos sociais, organizações não governamentais, partidos de esquerda, universidades públicas, Ministério Público, Defensoria Pública, entre outros.

Esses percursos permitem entrever a formação de uma verdadeira cartografia do agir militante, que não cessaria de se instituir, fazendo, desfazendo e refazendo trajetórias, laços, recursos e discursos. Esta cartografia de práticas variadas, originada das ações em contexto dos diversos atores sociais envolvidos nas disputas e conflitos que se constituem em torno das práticas de remoção de favelas, também seria formatada por um enquadramento moral e de regras específicas.

Nesse sentido, as ações levadas a cabo pelos indivíduos envolvidos nas disputas não partiriam do nada, como afirma Cefaï (2011). Segundo o autor,

os atores não inventam a partir do zero as justificações que dirigem ao público. Eles as buscam em repertórios de argumentações, típicas e recorrentes, identificáveis em outras situações de luta urbana. Por outro lado, eles também criam, dia após dia, os seus próprios argumentos, segundo os pontos estratégicos e específicos da situação local.

Portanto, para que o que ocorre faça sentido para si próprio e para legitimar as críticas diante dos diferentes públicos com os quais estas poderão se confrontar e para os quais elas se direcionam, precisam acionar elementos de repertórios militantes já constituídos, um "voca- 
bulário de motivos" (Mills, 1940; Trom, 2001), muito embora haja um espaço, que não pode ser negligenciado, de criatividade para novas formas e modalidades do agir militante e de encaminhamento de denúncias 9 .

Antes, contudo, cabe destacar a partir do que se articularia o próprio incômodo que levaria a ação e a constituição de inúmeras trajetórias, conformando uma "trama de publicização" da demanda em questão. Qual o substrato deste incômodo? O que faria com que as pessoas agissem? Em que ponto específico se localizaria a crítica a partir da qual todo um conjunto de ações será levado adiante? Qual regra (ou regras) e fins comuns tornaram possíveis que as ações empreendidas apontassem para a formação de um coletivo (ou coletivos)?

\section{“Não somos contra a obra, mas não aceitamos a forma como tem sido feito": a crítica central aos procedimentos}

Ao acompanhar a trajetória dos moradores de favelas em diversos espaços e arenas às quais recorriam para se fazerem ouvir em suas queixas e reclamações, pude observar que, independentemente de causas mais gerais serem mobilizadas para explicar os motivos pelos quais a prefeitura levava a cabo um amplo processo de realocação de favelas na cidade, a crítica primordial realizada pelos moradores nestas circunstâncias eram aos "procedimentos" ou, numa expressão muito comum nessa época, à "forma como é feita" a remoção pela administração pública.

Isto é, nesse período, o centro da crítica dos moradores de favelas nas ocasiões de remoção eram justamente as táticas e estratégias levadas a cabo pela administração pública. O que pareceu decisivo em toda a articulação de um enquadramento moral para a constituição e encaminhamento de denúncias foi exatamente a maneira, considerada inadequada, injusta e também arbitrária, pela qual se davam os processos de remoção.

Neste sentido, e buscando se ajustar à situação para que as demandas que faziam e a crítica que dirigiam ao público em geral e aos seus interlocutores principais - as agências estatais - fossem válidas e consideradas legítimas, os moradores de favelas em processo de remoção frequentemente afirmavam, sobretudo quando estavam diante de alguém que pudesse lhes dar alguma resposta (como o secretário de habitação do município ou outra autoridade pública), que eles não eram 
contra o "progresso" ou contra a realização das obras (notadamente nos casos de remoções que envolviam intervenções urbanísticas).

Ou seja, a questão por eles levantada diante daqueles que deveriam lhes oferecer alguma solução para o que consideravam ser um problema, era justamente o fato de que a concretização das inúmeras obras pela cidade, visando prepará-la para os Jogos Olímpicos de 2016, não deveria significar que apenas uma parte da população viesse a usufruir dos seus virtuais benefícios. Como afirmou um morador de uma favela, integrante do Conselho Popular, em uma das reuniões realizadas com autoridades do município:

na verdade, objetivamente, ninguém das comunidades é contra a obra. Sabe por quê? Porque a obra é desenvolvimento para melhorar a região. O que a gente coloca é que as pessoas não podem desfrutar, usufruir do desenvolvimento que a prefeitura está implantando.

Levando esta passagem em consideração e o que foi dito até aqui, poder-se-ia afirmar que a crítica aos "procedimentos" utilizados pela prefeitura para efetivar as remoções se constituiria em dois níveis: no primeiro, sobre como as intervenções poderiam impactar nas rotinas de vida e nas inúmeras redes de sociabilidade tão longamente constituídas no local de moradia. No segundo e, principalmente, em como esses processos são vistos pelos que são impactados como uma espécie de desqualificação moral.

No primeiro caso, embora se considere o fato de que a vida local seria eivada de inúmeros conflitos (marcada por desavenças, brigas, discordâncias), nas ocasiões de remoção, esta dimensão conflituosa seria suspensa, ou conviveria paralelamente a uma posição pública que ressaltaria o valor positivo de ali viver, de ali estar, a força dos laços estabelecidos com as pessoas e o lugar. Retirá-los dali, neste sentido, seria romper uma densa e rica rede de relações interpessoais, de trabalho e acesso a serviços que, segundo afirmam estes moradores, seria impossível reconstruir nos conjuntos para os quais a prefeitura pretendia levá-los ou em outros locais.

No segundo, embora não sejam contra a "remoção em si" e, principalmente, ao "progresso", rejeitariam a forma pela qual este último se efetivaria, cujos benefícios seriam vistos como desigualmente distribuídos espacial e socialmente. Isto ficaria demonstrado, como veremos adiante, em uma dupla crítica: inicialmente, ao tratamento dispensado 
pelos agentes públicos que atuam na ponta quando do contato estabelecido entre eles e os moradores das favelas que a administração pública pretendia retirar; segundo, ao tratamento dado pelas autoridades públicas às quais direcionavam suas queixas e quando questionam o fato de que "não seriam lixo" para serem tratados daquela maneira. Embora a linha que separa ambos os casos seja muito tênue (afinal, tratam da mesma questão, a desqualificação moral), haveria certa diferença de ênfase que dependeria da situação em que as críticas fossem mobilizadas.

Em suma, no primeiro caso, haveria uma reclamação de algo que os impactaria diretamente em sua rotina mais ordinária. As situações face a face com os agentes públicos que atuam na ponta foram muito intensas nos episódios de remoção ocorridos. No segundo, os moradores afirmam que, além de sofrerem com o que lhes dizem e fazem os funcionários das subprefeituras e da Secretaria Municipal de Habitação (SMH), também sofreriam com o descaso das autoridades públicas responsáveis em dar alguma resposta àquela situação, e que, na opinião deles, ignoraram as denúncias, quando não as deslegitimam.

\section{DESQUALIFICAÇÃO MORAL E FORMAÇÃO DA CRÍTICA PÚBLICA}

Privilegiarei, neste momento, o ponto da desqualificação moral presente na formulação da crítica aos procedimentos, e que é central na conformação do enquadramento da situação e da constituição da ação coletiva.

Em variadas situações, os moradores de favelas em processo de remoção, notadamente aqueles cujo engajamento nas ações de construção de denúncias os levavam a figurar como "porta-vozes" locais, apontaram e identificaram diferentes elementos que permitem compreender a composição da dinâmica de desqualificação moral - diante de outros moradores, em assembleias locais; nas reuniões do Conselho Popular; em encontros em instituições do Estado, como o Ministério Público e a Defensoria Pública, além, é claro, da SMH, Subprefeituras e com o próprio prefeito; ou ainda quando realizavam entrevistas para grandes meios de comunicação ou alternativos.

Quando as críticas se referiam (ou mesmo se dirigiam diretamente) à ação dos agentes públicos que atuavam na ponta do processo de convencimento e de remoção, elas mencionavam fundamentalmente o fato de que, em muitas ocasiões, os agentes desconsideravam ou mes- 
mo ironizavam a capacidade cognitiva e de avaliação da situação dos moradores envolvidos. Um exemplo sintomático disso ocorreu numa favela parcialmente removida em função da construção de uma via segregada para ônibus na Zona Norte da cidade. Entre outras formas de ação e condução utilizadas pelos agentes, e criticadas pelos moradores, estavam aquelas associadas à manipulação da informação quanto ao que de fato estava acontecendo e em relação ao que poderia vir a acontecer.

Neste local, as remoções já haviam iniciado. Num determinado dia, funcionários da subprefeitura local foram até a favela para retirar as pessoas que tinham sido convencidas de ir para o conjunto habitacional na Zona Oeste da cidade, onde a prefeitura tinha ofertado um novo imóvel. Havia dois funcionários. O primeiro tentava convencer os moradores e também um dos que tinham sido vistos como responsáveis por espalhar "ofensas" e realizar "ameaças". O outro atuava agilizando a mudança, verificando quem havia aceitado ir ou não. O que fazia o trabalho de convencimento conversava individualmente com alguns moradores, ou quando estes formavam pequenos grupos. Fazia isto incansavelmente, indo de um lado para o outro da localidade. Depois de certo tempo, um novo estado de tensão se constituía. Os moradores que se recusavam a sair afirmavam que, em função dessa insistente ação de convencimento, muitos outros acabaram "ficando com dúvidas" e aceitando a proposta da administração pública.

Um dos pontos que gostaria de ressaltar nas interações ocorridas nesse dia foi a maneira como um destes agentes da subprefeitura se apresentava. O que tratava da logística do processo (isto é, o responsável por conferir quem havia aceitado a oferta da prefeitura, organizar as mudanças e levá-los ao conjunto habitacional), enquanto circulava entre as casas, disse a um morador que era "espírita" e, assim sendo, "entenderia a situação", pedindo desculpas pelo que estava fazendo, apesar de ressaltar que apenas cumpria ordens. Logo após, em outra situação, enquanto conversava com um pastor local, apresentou-se como evangélico. Só que, diferentemente da outra inscrição social declarada, em que tentara se redimir pelo que fazia, desta vez afirmou que a "comunidade é nojenta", seguida da rejeição veemente do referido pastor. Ainda nesta ocasião, uma moradora tentou expor a um dos agentes sua vontade de ficar e, para apoiar seu posicionamento, afirmou-lhe que "a Defensoria e a lei" estavam do lado dela. Ele, de forma irônica, perguntou-lhe na sequência: "cadê a defensora, não estou vendo a defen- 
sora, será que ela está ali?". Em outro momento, este mesmo funcionário disse que a ajuda da Defensoria Pública não adiantaria, uma vez que as pessoas naquele local não tinham direito a nada. O responsável pela "logística" ainda disse aos moradores que se eles não saíssem até determinado dia - pois "até lá uma liminar poderia ser dada pelo juiz" -, as pessoas seriam retiradas de suas casas, seus pertences jogados na rua e a casa demolida.

Quando um morador tentou questioná-lo sobre a situação, mais uma vez o agente não reconheceu ou aceitou a crítica, afirmando que as pessoas ali precisavam "saber conversar", "precisavam aprender a falar", chamando o morador de "burro". "Saber conversar" e "precisar aprender a falar" se referiam, neste contexto, à forma como esse morador se expressava. Isto é, o agente público jogava, por um lado, com o fato de o morador não se expressar segundo a norma culta da língua para tornar clara sua reivindicação a fim de deslegitimá-la e, por outro lado, em função desta mesma "incapacidade", criticava-o por não saber o que estava dizendo ao mencionar o possível recurso à "Defensoria e à lei". À medida que os moradores relatavam e interpretavam essas formas de tratamento, demonstravam incômodo diante delas e as questionavam por meio de expressões como "eles acham que somos burros", "não sou idiota", "eles não podem nos tratar dessa maneira".

Outro procedimento usado pela prefeitura foram os cortes dos serviços públicos, como água e eletricidade, nas favelas nas quais o processo de remoção já havia sido iniciado. Isso ocorreu em pelo menos duas localidades cujo processo de remoção tive a oportunidade de acompanhar. Em uma delas, os cortes de serviços públicos começaram logo após a primeira investida da administração pública. Desconhecendo os motivos do ocorrido, os moradores de uma favela removida na Zona Norte em função de uma intervenção urbanística que alterou os usos daquele local (de moradia para área de lazer), foram surpreendidos pela interrupção dos serviços públicos, que atingiu toda a localidade. Como muitos estavam com as ligações regularizadas, tanto do serviço de água, quanto de eletricidade, um dos moradores entrou em contato com as companhias responsáveis pelo fornecimento desses serviços. Contudo, mesmo depois de ter registrado um pedido de restabelecimento, apenas a companhia de água foi ao local. A de eletricidade ignorou o pedido, sem maiores explicações, a despeito da insistência de outros moradores. Como forma de resolver o problema, a presidente da associação de moradores recorreu a mecanismos informais de resolução: contatou alguns conhecidos que sabiam lidar com redes elétri- 
cas para poder recuperar, informalmente, o fornecimento de energia elétrica local.

Os moradores passaram a interpretar esta ação, no contexto crítico do processo de remoção, como uma forma de pressão por parte da administração pública. Em uma reunião realizada no Ministério Público, diante de moradores de outras localidades e de promotores, um dos participantes que morava nessa localidade declarou: "a prefeitura está nos tratando como se não existíssemos mais". Esta reclamação, que dava forma à crítica aos procedimentos, apontava, mais uma vez, para o que venho afirmando até agora: as intervenções da administração pública nessas localidades e, especialmente, as interações estabelecidas entre agentes públicos e moradores, se traduziam nos termos de uma dinâmica de desqualificação moral. Na situação que acabei de relatar, o morador parecia reclamar do fato de que, apesar de muitas pessoas ainda estarem em suas casas e tentando manter algumas rotinas de vida, as agências estatais atuavam ignorando sua existência.

\section{O Argumento Técnico, Queixas e Críticas}

Outra modalidade de queixa relacionava-se aos critérios utilizados pela administração pública para justificar e realizar os processos de remoção, bem como sua publicidade. Haveria aqui dois níveis distintos de crítica, os quais variavam de acordo com o motivo alegado para efetuar a realocação: de um lado, a crítica em torno da queixa sobre os limites necessários para a execução de uma determinada obra (normalmente as inúmeras obras viárias que foram ou têm sido levadas a cabo pela prefeitura e interferem em diversas regiões da cidade). Por outro, a crítica que se constituía em torno de uma reclamação acerca da alegação da administração pública de que o local de moradia atual seria impróprio para morar por se tratar de uma "área de risco".

No primeiro caso, especialmente quando estavam diante de agentes públicos que teriam, em tese, alguma responsabilidade sobre a situação que estavam vivenciando, os moradores questionavam sobre o traçado da referida obra viária. Esta seria uma das questões que compunham o "tempo do rumor", isto é, o tema de como se acessa e faz circular a informação sobre o que vai acontecer num determinado local é fonte de rumores acerca da virtual remoção. Tornou-se comum ouvir nas conversas cotidianas frases como esta: "mas quantos metros serão necessários para dentro da comunidade?". 
Quando alguns deles se organizavam para tentar impedir o processo de realocação, um dos primeiros passos é justamente obter informações por parte da administração pública sobre a natureza da intervenção urbanística. Isto quase sempre se faz por meio de pedidos realizados pelo Nuth. Esses pedidos eram a primeira tentativa daqueles que se recusavam a sair para estabelecer uma negociação com as agências públicas envolvidas que levasse em consideração a permanência deles.

Dessa maneira, os defensores públicos acorriam à produção de ofícios com o fito de exigir ambas as coisas: ao passo que demandavam acesso ao projeto que indicasse o cronograma e as ações da referida intervenção, solicitavam que, a partir deste, se rediscutissem os termos da necessidade da remoção. Entretanto, em quase todas as ocasiões que pude acompanhar, e observando o trâmite desses ofícios no Nuth, as respostas provenientes da administração pública - quando havia - ou eram insuficientes e pouco esclarecedoras, ou simplesmente ignoravam as demandas dos moradores. Isto apenas fazia aumentar as incertezas quanto a "real" necessidade de se remover a localidade, já que nenhum detalhe técnico havia sido fornecido aos moradores ou aos seus coletivos (notadamente o Nuth) para que eles próprios pudessem avaliar e discutir a justeza da intervenção urbanística.

O morador de uma favela que estava sendo removida por causa de uma dessas obras viárias, quando esteve diante do secretário de Habitação, expressou justamente essa inquietação relacionada com a questão técnica, que lhe parecia central no entendimento do que estava ocorrendo na localidade em que morava. Ele apontou para o fato de que, num primeiro momento, agentes da subprefeitura que haviam estado no local bem no início do processo de realocação afirmaram que a intenção seria demarcar, a partir da avenida a ser alargada, algo como 45 metros para dentro da localidade. Entretanto, posteriormente, isto veio a ser alterado para 26 metros.

Apesar dessa indefinição, as casas existentes no local vieram a ser marcadas aleatoriamente e foi nesse ponto que o morador centrou seu questionamento. Isto é, independentemente da confirmação do exato perímetro em cuja localização estariam as casas que deveriam sair (e, portanto, aquelas que ficariam), a ação da prefeitura teve início sem maiores explicações. Segundo o relato desse morador, muitas casas foram marcadas mesmo estando a 100 metros de distância de onde se alegara inicialmente. Outras, mais próximas da avenida, não foram mar- 
cadas. Isso criou uma situação na qual, uma casa podia ser marcada e a casa ao lado, não. Tal aleatoriedade constituiu justamente a causa das queixas nesse caso e orientou a crítica aos procedimentos utilizados pela administração pública.

No outro caso, as reclamações que orientavam a formação e veiculação da crítica se deram em torno da natureza dos argumentos técnicos que eram mobilizados por agências estatais (objetivados em determinados laudos) para definir uma determinada área como de risco ou não. Quando analisei a constituição do "repertório da remoção" (Magalhães, 2013), uma das justificativas acionadas para configurar o enquadramento que autorizaria as intervenções do tipo erradicação era justamente a questão do risco. Essa justificativa foi aplicada especialmente após as chuvas de abril de 2010, quando ocorreram mais de 250 mortes em favelas da cidade do Rio de Janeiro e em outras no Estado. Logo após aquele evento climático, a prefeitura apresentou um laudo do Instituto de Geotecnia (Geo-Rio), no qual se apresentava uma argumentação, baseada em algumas fotos de satélite, que sustentava a necessidade de remover imediatamente, naquele momento, oito favelas.

Como o tipo de prova necessária para justificar e sustentar as intervenções do tipo erradicação em um contexto como esse já havia sido produzido, independentemente da explicitação da maneira com que fora realizado (o contexto crítico aberto naquele momento favoreceu uma atitude como esta), as remoções se iniciaram em seguida. Entretanto, em uma das localidades apontadas naquele documento como estando em "área de risco", situada na Zona Sul da cidade, alguns moradores contestaram a definição feita pela administração pública. Eles interrogaram justamente a falta de explicitação dos critérios utilizados para definir a região como de "risco".

Um dos primeiros argumentos oferecidos foi o fato de que, há quase trinta anos, a própria administração pública havia reassentado ali pessoas oriundas de outras partes daquela localidade. Este caso levou à seguinte pergunta feita numa situação de denúncia pública realizada a um ministro de Estado: "como antes não era área de risco e agora é?". Em segundo lugar, os moradores argumentaram que o laudo elaborado pelo Geo-Rio não teria considerado que, naquela ocasião, nenhuma casa havia sido atingida pelo único deslizamento ocorrido no local, que aconteceu apenas num trecho de uma rua que passa pela localida- 
de e não teria, portanto, ocasionado nada que levasse a definir a área como imprópria para morar.

Desse modo, as queixas dos moradores nas ocasiões em que se alegava o fator "risco" como justificativa para remover surgem em torno da "veracidade" das informações presentes nos laudos apresentados pela administração pública. Isto é, questionava-se, fundamentalmente, nestes documentos, sua natureza de "prova de realidade" mobilizada pela administração para apoiar a intervenção do tipo erradicação.

Dito isto, me parece possível afirmar que as duas críticas dizem respeito à "real" necessidade da remoção de uma determinada localidade. Muitas das ações posteriores, constituídas no bojo da busca por informações e no processo de publicização da causa, deram-se a partir da crítica a esses critérios, que seriam colocados em questão pelas provas mobilizadas pelos coletivos e indivíduos envolvidos na dinâmica de tornar público o problema da remoção de favelas. Uma das formas se refere aos "contralaudos". Buscando se ajustar à situação, os moradores também se apoiaram em argumentos considerados técnicos (neste caso, da engenharia) para sustentar suas críticas quanto à necessidade da remoção, sobretudo a partir da alegação de que uma determinada área estaria em "risco".

\section{MODULAÇÕES DAS CRÍTICAS: A QUESTÃO DO "ESFORÇO" E 0 RELAXAMENTO COGNITIVO}

Outras modalidades de queixas e reclamações se constituíram a partir da forma como os moradores, destacando elementos do contexto imediatamente vivido, avaliavam e interpretavam o que lhes acontecia. Uma destas modalidades se refere à questão do "esforço", destacado pelos moradores como a maneira por eles escolhida de tornar compreensível a ruptura que as ações de remoções haviam representado em suas vidas. Na tentativa de compreender o que estava acontecendo, esses moradores recontavam sua própria história, refazendo suas trajetórias e apontando os momentos de superação do que chamavam de "dificuldades" para obter o imóvel em que moravam, e como este período teria levado a uma espécie de relaxamento cognitivo representado pela estabilização das rotinas, algo que apenas seria interrompido pelos processos de remoção.

Moradores alegam que um dos elementos ignorados pela administração pública nessas ocasiões é justamente seu esforço, notadamente 
aquele relacionado à estabilização das rotinas de vida. Uma moradora de uma localidade situada em um subúrbio da cidade, que estava sendo removida sob a alegação de estar em área de "risco", enfatiza esta questão do "esforço" como algo importante na constituição do que entendia ser o seu direito à moradia. Em entrevista realizada por mim, ela classificou a situação como "inoportuna", na medida em que, conforme sua afirmação, a prefeitura lhe oferecia algo que, primeiro, ela não havia pedido, e, segundo, que "não teria a minha cara", isto é, todo o investimento, notadamente afetivo, que ela havia realizado ali. Neste sentido, ressaltou o fato de que, apesar de sua casa "não ter luxo", em vista do que supostamente seriam os novos imóveis para os quais as pessoas iam ser levadas - segundo ela, "muito inferiores" -, preferiria permanecer onde estava.

Mais uma vez, neste caso, o destaque se dá justamente no investimento afetivo, configurado pela mobilização do termo "esforço", ressaltando tudo o que ela própria fez ou teve que enfrentar para obter uma moradia. Desse ponto de vista, teria sido importante acompanhar de perto a construção do imóvel, algo feito desde o "barraco", que ela ocupava com a filha, até a casa de alvenaria.

Ter acompanhado todo esse processo significava, contudo, saber que a casa fora "muito bem feita" e, portanto, não fazia sentido o argumento da administração pública de que ela não resistiria a possíveis vetores de risco, como era a alegação principal:

porque a construção dessa casa, o projeto dela embaixo do chão ainda bota mais dois andares em cima, com segurança, tranquila, entendeu? Porque eu vi as fundações, acompanhei, tava aqui morando embaixo da minha casa, num barraquinho.

Erigir um imóvel significava superar uma situação desconfortável e problemática, associada justamente ao fato de morar no "barraquinho". Ter a casa seria uma forma de melhorar de vida e de afastar, definitivamente, os vetores das dificuldades. Neste sentido, destacar o que se enfrentava fazia parte desta modalidade de queixa direcionada às práticas da administração pública:

(...) enfrentei muita enchente aqui, saí com minha filha jovem, adolescente, para sair daqui com enchente com água na cintura, entendeu. Quinze para meia noite, uma hora da manhã, lá para casa da sogra da minha filha, que na época éramos colegas de trabalho, e ia dormir lá. E 
chegava 2 horas da manhã na casa dela. Para tomar banho, passar álcool nas pernas, nos braços, porque saía daqui com enchente. E para lavar, para tirar aquelas sujeiras de lama podre de dentro de casa. Porque antes de sair a gente fazia uma mudança dentro de casa, dentro do barraco, porque a gente tinha que levantar tudo, para não perder tudo na época, onde já perdi geladeira, televisão, estante. Perdi! Perdi! Porque enchia e não dava tempo para pegar, e quando voltava no dia seguinte estava tudo cheio de água. O que tinha que fazer? Jogar fora.

Hoje, sem mais nem menos a prefeitura chegar dizendo que eu tenho que sair da minha casa? É não fazer reconhecer o sacrifício da gente, do pobre. É como se diz: querer tomar na mão grande. Eu sou muito mais a minha casa do que essas casas, esses apartamentos que eles constroem. Porque eu acompanhei aqui a obra da minha casa.

Portanto, a intervenção estatal visando a realocação dos moradores destas localidades não leva em conta esse aspecto de suas vidas - isto é, todo o "esforço" que tinham feito para estarem ali. Além disso, outra dimensão dessa modalidade de questionamento diz respeito ao fato de que as ações de remoção levariam à ruptura no nível das inter-relações estabelecidas entre os que ali moravam.

Destacando-se, mais uma vez, a questão da possibilidade de manter a rotina tal e qual era vivenciada até aquele momento, os moradores de favelas em processo de remoção apontavam justamente para o fato de que um dos elementos por eles tratados como significativo fora rompido, qual seja, os "laços" que haviam dura e longamente estabelecido com seus vizinhos e com o entorno.

Além do mais, o fato de terem em dado momento de suas vidas estabilizado uma rotina, especialmente no que se refere à questão da moradia (que deixara de ser algo com o qual precisavam estar sempre preocupados), lhes permitira estabelecer também uma determinada circulação pela cidade e acessar certos serviços públicos ou privados, como os de lazer. Todos esses elementos seriam responsáveis por conformar o que muitos chamavam de "raízes", isto é, uma espécie de ponto de ancoragem cognitivo e moral que agora estava sendo colocado em questão pela intervenção estatal. Portanto, neste sentido, a crítica exprimia uma defesa da permanência: "Ninguém aqui quer ir para [bairro para onde a prefeitura pretendia levá-los], pois nossas raízes estão no [bairro onde moravam], nós temos família ali, construímos nossa vida social ali, queremos continuar no nosso bairro"10. 
Desta forma, portanto, ao criticarem a formação do processo que estou chamando de desqualificação moral, esses moradores apontam para a constituição de um "bem comum" (Boltanski e Thévenot, 1999), necessário à coordenação de suas ações, que não necessariamente dizia respeito apenas à habitação propriamente dita, mas, fundamentalmente, à possibilidade de também pertencerem à cidade e aos benefícios que poderiam advir das transformações que vêm ocorrendo nos últimos anos. A defesa do "direito de permanecer" onde se estabeleceram e estabilizaram determinadas rotinas de vida (trabalho, lazer) significaria permanecer e ser levado em consideração quanto aos benefícios do "progresso", que não seria rejeitado, como já afirmado, mas que não os incluiria.

Outro nível de elaboração da crítica se constitui não a partir de certo regime de proximidade (Thévenot, 2006), isto é, das queixas que se dão no registro daquilo que é vivenciado e experimentado na vida cotidiana dos moradores de favelas em processo de remoção, como a experiência afetiva com o local e com a própria casa. Embora a experiência de rompimento das rotinas de vida seja o impulsionador do tipo de engajamento posteriormente observado nas trajetórias realizadas por essas pessoas para levar adiante a sua denúncia, nos percursos que elas constituíram para tornar público o problema da remoção, as queixas por elas manifestadas se transformarão com o contato e o acionamento de repertórios militantes já existentes. Neste sentido, a articulação com redes movimentalistas levaria ao acionamento de outras razões para explicar a maneira pela qual a administração pública tem levado a cabo os processos de remoção.

Muitas organizações e movimentos sociais que vão sendo contatados ou incorporados à construção da denúncia pública dessas situações já possuíam alguma experiência anterior em casos como os que aqui vêm sendo discutidos, isto é, de ocasiões de realocação em outros períodos e lugares. Essa experiência formatou determinados modos de agir e também tipos de enquadramento de situações parecidas, e que configuram referências às quais se poderia recorrer para esclarecer e dotar de sentido as experiências que ganhavam forma naquele momento.

Quanto a isso, cabe destacar que uma das maneiras de compreender o que vem acontecendo atualmente no Rio de Janeiro é o acionamento da expressão "limpeza social", que interpela os processos associados às 
intervenções urbanísticas que ocorreram nos últimos anos na cidade, notadamente aquelas ligadas à preparação para a realização de megaeventos esportivos, como a Copa do Mundo de 2014 e os Jogos Olímpicos de 2016.

Nas variadas situações em que pude observar o uso desta expressão, ela parecia questionar, a partir de um enquadramento específico da situação, um conjunto de fenômenos que dizia respeito a maneiras de ocupar e usar a cidade. Esses usos da cidade, nesta elaboração e na atual conjuntura, não estariam levando em consideração a participação dos moradores de favelas na constituição da cidade. Tal abordagem acerca das intervenções estatais no espaço urbano não seria uma novidade. Ou seja, em outros períodos da história urbana do Rio de Janeiro as práticas ditas "corretivas" da administração pública também já teriam ocasionando deslocamentos populacionais.

Costuma-se fazer referência a dois exemplos históricos para situar esta elaboração: a Reforma Pereira Passos, ocorrida no início do século XX, quando os cortiços que existiam no Centro da cidade foram postos abaixo e parte daquela população iria ocupar, posteriormente, a localidade que hoje é conhecida como Morro da Providência; e, principalmente a política de remoções de favelas iniciada pelo governador do então Estado da Guanabara, Carlos Lacerda, nos anos 1960. Contudo, atualmente, embora se apresentem os acontecimentos como decorrendo de certa continuidade temporal (ou seja, as práticas estatais nas favelas seriam as mesmas desde o início do século XX), foram atualizadas a partir do contexto da realização dos referidos megaeventos esportivos.

"Limpeza social", neste enquadramento, portanto, apontaria para um aspecto da intervenção estatal no espaço urbano que ignora a presença e os direitos dos moradores de favelas e cuja intenção seria liberar determinadas áreas apenas para favorecer os vetores do capital imobiliário. Além do mais, é possível ressaltar o fato de que essa expressão cria uma espécie de conexão simbólica entre a ação estatal visando a retirada daqueles que são vistos como um incômodo e a valorização e incremento do mercado imobiliário. Neste sentido, como afirmam alguns dos militantes que já se engajaram em outras mobilizações coletivas relacionadas à questão da moradia e das favelas, a intervenção estatal vi- 
saria tão somente à defesa dos interesses dos grupos econômicos ligados ao capital imobiliário.

\section{CONCLUSÕES}

Neste artigo, busquei demonstrar a construção da crítica pública aos processos de remoção de favelas que ocorreram (e ainda ocorrem) na cidade do Rio de Janeiro nos últimos anos. Minha intenção foi apresentar os argumentos a partir dos quais os moradores dessas localidades, bem como outros coletivos, transformaram um problema que dizia respeito a um grupo restrito em um problema público que demandava uma resposta coletiva.

Essa elaboração articulou-se em torno do que denominei de desqualificação moral, processo que indicava a maneira pela qual as pessoas eram tratadas pela administração pública, tanto pelos agentes que atuavam na ponta destas situações de remoção, quanto pelos gestores responsáveis pelas decisões que as iniciavam. Neste ponto, os moradores de favelas não questionavam a "remoção em si", mas a desconsideração ou mesmo a ironia dos agentes quanto à sua capacidade cognitiva e de avaliação das situações.

O que se questionava era justamente a desigual distribuição dos benefícios do "progresso" que a realização de obras pela cidade estaria produzindo. Mais do que isso, neste mesmo processo, sua condição de humanos era rebaixada, pois que tratados como "lixo", tal como afirmaram em diversas ocasiões ao longo dos processos de remoção.

Por conta desta situação, a defesa do "direito de permanecer" onde lograram estabilizar suas rotinas de vida, efetivando seu direito à habitação e à cidade, significaria a persistência em ser levado em consideração quanto aos benefícios do "progresso".

(Recebido para publicação em maio de 2015)

(Reapresentado em janeiro de 2016)

(Aprovado para publicação em outubro de 2016) 


\section{Críticas e Denúncias: A Configuração da Ação Coletiva contra a Remoção...}

\section{NOTAS}

1. Importante destacar que quando me refiro à "redefinição" e/ou "reatualização" da remoção de favelas como um problema público, estou aludindo ao fato de que, embora a problemática seja a mesma que aquela dos anos de 1960 e 1970, o contexto ao qual ela está indexada atualmente se modificou consideravelmente. Os referenciais de sentido que motivavam a ação estatal nas favelas e as justificativas ajustadas a estes se alteraram, embora, repito, a problemática seja a mesma. Dada a impossibilidade de recuperar, no curto espaço deste artigo, a variação conjuntural do termo remoção ao longo do tempo, sugiro a consulta a diferentes pesquisas que abordaram a questão, ainda que de perspectivas diferentes. Ver, sobretudo, Valladares (1978), Gonçalves (2013), Brum (2012).

2. Tal termo, historicamente associado ao campo semântico que constitui a favela como um "problema", pode aqui ser entendido de diferentes maneiras, haja vista sua polissemia. Em relação a essas localidades, muitas vezes a expressão "risco" variou entre uma condição física ligada às características geomorfológicas do território, até aquela associada a um suposto comportamento de quem o habitava. Quando se aciona a expressão "áreas de risco", imediatamente vem a mente uma dupla imagem: de um lado, casas construídas em ribanceiras ou em beiras de risco; de outro, uma área que se deve evitar, pois de lá se originaria a violência que assola o restante da cidade. No caso em tela, a associação reforçada naquele contexto, ainda que não ignorasse esta última injunção, privilegiou o aspecto geomorfológico.

3. A expressão "os moradores de favelas", utilizada de forma genérica ao longo do texto, aponta para um amplo processo vivenciado por inúmeras pessoas, de diferentes favelas e regiões da cidade. Ou seja, ela condensa uma dinâmica mais geral ocorrida no Rio de Janeiro, independentemente das suas aparições locais. Quando necessário à análise, utilizarei a expressão adicionando a região onde uma determinada favela em processo de remoção está situada.

4. Para um recente histórico analítico sobre as interpretações dos movimentos sociais no Brasil, ver Bringel e Teixeira (2015).

5. Ainda segundo Trom (2001), uma determinada entidade atuante, como, por exemplo, um "movimento social", seria suscetível de ser apreendido como um encadeamento ou uma concatenação espaço-temporal de atuações observáveis empiricamente.

6. Este artigo é baseado em minha tese de doutorado, momento no qual analisei os processos de remoção de favelas ocorridos nos últimos anos na cidade do Rio de Janeiro. Visitei aproximadamente 30 localidades entre 2009 e 2012, em diferentes regiões da cidade e fases do processo de remoção. Acompanhei mais detidamente algumas destas experiências, das quais destaco as das favelas Metrô-Mangueira, Vila das Torres, Campinho, Parque Colúmbia (todas na Zona Norte), Estradinha-Tabajaras (Zona Sul), Vila Recreio II, Vila Harmonia, e Vila Autódromo (todas na Zona Oeste). Acompanhar ocasiões de realocação em diversas áreas da cidade me permitiu confirmar o aumento de escopo na atuação da administração pública em relação a este tipo de intervenção sobre esses territórios. O tratamento das informações apresentadas se constituiu a partir do acompanhamento in loco destas dinâmicas, da consideração da miríade de documentos estatais e não estatais produzidos pelos atores coletivos envolvidos e da produção midiática acerca do assunto. Esses materiais permitiram re- 


\section{Alexandre Magalhães}

construir as narrativas que fundamentaram a elaboração do enquadramento cognitivo e moral da ação coletiva e suas consequências na estruturação de certo campo movimentalista em torno deste tema.

7. Excerto de entrevista realizada com uma moradora de uma favela em processo de remoção no subúrbio da cidade do Rio de Janeiro no final de 2011.

8. Nestas situações de tensão, segundo esses autores, operações de ajuste a uma dada realidade e de coordenação das ações se colocam mais claramente e podem ser observadas. Seria este o momento em que se descortina o horizonte da copresença e no qual se colocaria a questão da explicitação das ações.

9. Trom (2001) afirma que em conjunto com um repertório clássico da ação coletiva se posicionaria uma variedade de atos de queixa, reclamações, protestos e mesmo reivindicações que configurariam uma determinada gramática política com o objetivo de aceder à visibilidade e à legitimidade pública.

10. Intervenção de um morador durante reunião com o secretário de Habitação do Rio de Janeiro em maio de 2010. 


\section{REFERÊNCIAS BIBLIOGRÁFICAS}

ALONSO, Ângela. (2009), "As Teorias dos Movimentos Sociais: Um Balanço do Debate". Lua Nova, no 76, pp. 49-86.

BOLTANSKI, Luc; CHIAPELLO, Eve. (2002), El Nuevo Espíritu del Capitalismo. Madrid, Ediciones Akal.

BOLTANSKI, Luc; THÉVENOT, Laurent. (1999), "A Sociologia da Capacidade Crítica". European Journal of Social Theory, vol. 3, no 2, pp. 359-377.

BRINGEL, Breno; TEIXEIRA, Marco Antônio. (2015), “Repertórios de Ação e Repertórios de Interpretação: Trinta Anos de Estudos sobre os Movimentos Sociais no Brasil", in I. Scherer-Warren; L. Luchmann (orgs.), Movimentos Sociais e Engajamento Político: Trajetórias e Tendências Analíticas. Florianópolis, Editora UFSC, pp. 43-76.

BRUM, Mário. (2012), Cidade Alta: História, Memóriase Estigma de Favela num Conjunto Habitacional do Rio de Janeiro. Rio de Janeiro, Ponteio.

CARDOSO, Ruth. (1984), "Movimentos Sociais Urbanos: Balanço Crítico", in B. Sorj; M. H. T. de Almeida (orgs.), Sociedade e Política no Brasil Pós-64. São Paulo, Brasiliense.

CEFAÏ, Daniel. (2011), “Qu'est-ce qu'une Arene Publique? Quelques Pistes pour une Approche Pragmatiste", in D. Cefaï; I. Joseph (eds.), L'Heritage du Pragmatisme. Conflits d'Urbanité et Épreuves de Civisme. La Tour d'Aigues, Éditions de l'Aube.

. (2009), "Como nos Mobilizamos? A Contribuição de uma Abordagem Pragmatista para a Sociologia da Ação Coletiva". Dilemas: Revista de Estudos de Conflito e Controle Social, vol. 2, no 4, pp. 11-48.

. (2002), “Como uma Associação Nasce para o Público: Vínculos Locais e Arena Pública em Torno da Associação La Bellevilleuse em Paris", in D. Cefaï et al. (orgs.), Arenas Públicas: Por uma Etnografia da Vida Associativa. Niterói, EDUFF.

DOIMO, Ana Maria. (1995), A Vez e a Voz do Popular: Movimentos Sociais e Participação Política no Brasil pós-70. Rio de Janeiro, Relume-Dumará/Anpocs.

FREIRE, Jussara. (2005), Sensos do Justo e Problemas Públicos em Nova Iguaçu. Tese (Doutorado em Sociologia). Instituto Universitário de Pesquisas do Rio de Janeiro, Rio de Janeiro.

GOFFMAN, Erving. (2009), A Representação do Eu na Vida Cotidiana. Petrópolis, Vozes.

GOHN, Maria da Glória. (2008), Novas Teorias dos Movimentos Sociais. São Paulo, Loyola.

GONÇALVES, Rafael Soares. (2013), Favelas do Rio de Janeiro: História e Direito. Rio de Janeiro, Pallas/Ed. PUC-Rio.

HIRATA, Daniel. (2010), Sobreviver na Adversidade: Entre o Mercado e a Vida. Tese (Doutorado em Sociologia). Universidade de São Paulo, São Paulo.

MACHADO DA SILVA, Luiz Antônio; RIBEIRO, Ana Clara. (1984), Paradigmas e Movimento Social: Por onde Andam nossas Ideias? Trabalho apresentado no 8 Encontro Anual da Anpocs, 23-26 de outubro, Águas de São Pedro, São Paulo.

MAGALHÃES, Alexandre. (2013), Transformações no "Problema Favela" e Reatualização da Remoção no Rio de Janeiro. Tese (Doutorado em Sociologia). Instituto de Estudos Sociais e Políticos, Universidade do Estado do Rio de Janeiro, Rio de Janeiro. 


\section{Alexandre Magalhães}

MILLS, C. Wright. (1940), "Situated Action and the Vocabulary of Motives". American Sociological Review, vol. 5, no 6, pp. 904-913.

SANTOS, Carlos Nelson Ferreira dos. (1981), Movimentos Urbanos no Rio de Janeiro. Rio de Janeiro, Zahar.

TELLES, Vera. (2010), A Cidade nas Fronteiras do Legal e Ilegal. Belo Horizonte, Argvmentvm.

TOURAINE, Alain. (2006), "Na Fronteira dos Movimentos Sociais". Sociedade e Estado, vol. 21, no 1, pp. 17-28.

THÉVENOT, Laurent. (2006), L'Action au Pluriel: Sociologie d'Engagement. Paris, La Découverte.

TROM, Danny. (2001), "Grammaire de la Mobilisation et Vocabulaires de Motifs", in D. Cefaï; D. Trom (orgs.), Les Formes de l'Action Collective. Mobilisation dans des Arènes Publiques. Paris, École des Hautes Études en Sciences Sociales.

VALLADARES, Licia. (1978), Passa-se uma Casa: Análise do Programa de Remoção de Favelas do Rio de Janeiro. Rio de Janeiro, Zahar Editores. 


\section{RESUMO \\ Críticas e Denúncias: A Configuração da Ação Coletiva contra a Remoção de Favelas do Rio de Janeiro}

Este artigo analisa os significados da reatualização de práticas e discursos sobre a "remoção" de favelas no Rio de Janeiro, abordando a formação da ação coletiva por parte dos moradores no período compreendido entre 2009 e 2012. Busca-se compreender como as concepções destes atores acerca deste assunto interferem em sua definição enquanto problema público. A crítica primordial realizada pelos moradores nestas circunstâncias seria aos "procedimentos", ou seja, à "forma como é feita" a remoção pela administração pública. Esta crítica se constitui em dois níveis: no primeiro, como estas intervenções afetariam as rotinas de vida e as inúmeras redes de sociabilidade tão longamente constituídas no local de moradia. No segundo nível, a questão central vincula-se a como estes processos são vistos pelos impactados como uma espécie de "desqualificação moral".

Palavras-chave: favelas; remoções; crítica; problema público; ação coletiva

\section{ABSTRACT \\ Criticism and Complaints: The Format of Collective Action Targeting the Removal of Favelas in Rio de Janeiro}

This article analyzes the impact of updates to practices and discourses on the "removal" of favelas in Rio de Janeiro, discussing the format adopted by collective actions organized by residents in the period from 2009 to 2012. With the study seeking to understand how perceptions shared by these actors on the issue interfere with its definition as a public problem, the main line of criticism taken by the residents in such circumstances targets the "procedure", i.e. "the way in which" removal is carried out by the public authorities. This complaint is made across two levels, with the first directed at how the interventions affect the daily lives and numerous, long-established sociability networks in the area, and the second concerning the central question of how these processes are seen by those impacted as a kind of "moral disqualification".

Key words: favelas; removals; criticism; public problems; collective action 


\section{RÉSUMÉ}

Critiques et Dénonciations: La Configuration de l'Action Collective contre l'Expulsion des Favelas de Rio de Janeiro

Cet article analyse les différentes significations des nouvelles pratiques et discours sur 1'"expulsion" des favelas de Rio de Janeiro et s'intéresse en particulier à la configuration de l'action collective des habitants entre 2009 et 2012. On cherchera comprendre de quelle manière les conceptions de ces acteurs interfèrent dans la définition de la situation en tant que problème public. La critique primordiale réalisée par les habitants touche en priorité les "procédures", c'est-à-dire la "façon dont sont réalisées" les expulsions par les pouvoirs publics. Cette critique se construit à deux niveaux. En premier lieu, l'accent est mis sur la manière dont ces interventions affectent les routines quotidiennes et les innombrables réseaux de sociabilité si patiemment construits sur le lieu de résidence. Dans un second temps, la question centrale est liée à la manière dont ces processus sont vécus par les personnes touchées, à savoir comme une sorte de "disqualification morale".

Mots-clés: favelas; expulsions; critique; problème public; action collective

\section{RESUMEN \\ Críticas y Denuncias: La Configuración de la Acción Colectiva contra el Desalojo de Favelas en Rio de Janeiro}

Este artículo analiza el significado de las nuevas prácticas y discursos sobre el desalojo de favelas en Rio de Janeiro, abordando la formación de la acción colectiva por parte de sus habitantes entre 2009 y 2012. Se busca comprender la forma en que la percepción que estos actores tienen de la situación interfiere en su consideración como un problema público. En estas circunstancias, los residentes critican especialmente el modus operandi, es decir, la "manera de proceder" al desalojo por parte de la administración pública. Esta crítica aborda dos niveles: en primer lugar, la forma en que tales intervenciones afectan a las rutinas diarias y a las innumerables redes de sociabilidad tan ampliamente constituidas en los barrios de las favelas. En segundo lugar, la cuestión central está vinculada a la manera en que los afectados ven este tipo de procesos que, a su juicio, son una especie de "descalificación moral".

Palabras clave: favelas; desalojo; crítica; problema público; acción colectiva 